\begin{tabular}{|c|c|c|}
\hline Case Reports in & \multicolumn{2}{|c|}{ Case Rep Gastroenterol 2019;13:423-429 } \\
\hline Gastroenterology & $\begin{array}{l}\text { DOI: 10.1159/000494749 } \\
\text { Published online: October 1, } 2019\end{array}$ & $\begin{array}{l}\text { (c) } 2019 \text { The Author(s) } \\
\text { Published by S. Karger AG, Basel } \\
\text { www.karger.com/crg }\end{array}$ \\
\hline & $\begin{array}{l}\text { This article is licensed under the } \\
\text { International License (CC BY-NC) } \\
\text { Usage and distribution for commer }\end{array}$ & $\begin{array}{l}\text { nons Attribution-NonCommercial } 4.0 \\
\text { ger.com/Services/OpenAccessLicense). } \\
\text { uires written permission. }\end{array}$ \\
\hline
\end{tabular}

\title{
An Entirely Atypical Presentation of Esophageal Squamous Cell Cancer with Pancreatic and Bone Metastases
}

\author{
Eric Yoon ${ }^{a}$ Yousef Nassar ${ }^{b} \quad J u a n$ Tejada-Almonte ${ }^{a}$ \\ Muhammad Sohail Mansoor ${ }^{\mathrm{a}}$ Kavita Umrau $^{\mathrm{c}}$ Sven Hida ${ }^{\mathrm{a}}$ \\ aDivision of Gastroenterology, Albany Medical Center, Albany, NY, USA; bDepartment of \\ Medicine, Albany Medical Center, Albany, NY, USA; 'Department of Pathology, Albany \\ Medical Center, Albany, NY, USA
}

\section{Keywords}

Esophageal squamous cell carcinoma - Squamous cell carcinoma of the pancreas - Metastasis to pancreas

\section{Abstract}

Few cases of solitary pancreatic metastases from esophageal cancer have been reported; however, these previous cases all describe a solid pancreatic mass. We present a unique case of a 67 -year-old man with squamous cell carcinoma detected within a pancreatic cystic lesion that was sampled with endoscopic ultrasound-guided fine needle aspiration. Esophagogastroduodenoscopy identified a friable and fungating partially obstructing mass in the distal esophagus with features of fistulization into the lung. Pathology showed esophageal squamous cell cancer. An isolated bone lesion was also biopsied and revealed squamous cell cancer. The patient tolerated oral intake and a multidisciplinary decision was made for palliative care with home hospices given his comorbidities portending poor operative candidacy and overall poor prognosis secondary to multiple sites of metastases from his esophageal squamous cell cancer. 


\section{Introduction}

Consideration of pancreatic malignancy is divided into exocrine versus an endocrine neoplasm. Within the umbrella of exocrine pancreatic malignancies, adenocarcinoma predominates at a rate of up to $80 \%$ of all pancreatic malignancies [1]. The normal pancreas entirely lacks squamous cells. A finding of squamous cells in a discrete pancreatic lesion usually denotes an undiagnosed primary squamous malignancy from a distant anatomic site [2].

There have only been a few reports of esophageal cancers leading to pancreatic metastases. Quint et al. [3] found 1 case out of 147 patients (0.68\%) with distal metastases to the pancreas from an esophageal cancer. Chan et al. [4] reported that pancreatic metastases from esophageal carcinoma occurred at a rate of 3.9\%. Herein, we present a unique case of synchronous pancreatic and bone metastases of an esophagobronchial fistulizing squamous cell carcinoma, with a brief literature review.

\section{Case Report}

A 67-year-old male presented to our tertiary care hospital complaining of worsening shortness of breath associated with increased productive cough. He had a weight loss of $50 \mathrm{lb}$ over the preceding 4 months. Initial physical examination revealed normal vital signs and left lower lobe crackles on auscultation of the lungs and an enlarged cervical lymph node. Examination was otherwise unremarkable.

Initial laboratory values showed a white blood cell count of $25.2 \mu \mathrm{L}$, hemoglobin of 10.3 $\mathrm{mg} / \mathrm{dL}$ with normal bilirubin and aminotransferases. Computerized tomography (CT) images revealed a 9.6-cm cavitary lung lesion with air-fluid levels, pretracheal lymph nodes, hepatic mass, vertebral osteolytic lesion, and a left adrenal mass.

The initial impression was that the lung lesion was secondary to recurrent aspiration pneumonia. There was also concern about a paraesophageal cystic fluid collection and thus bronchoscopy was deferred in lieu of endoscopy.

Esophagogastroduodenoscopy (EGD) with endoscopic ultrasound (EUS) was scheduled to evaluate the patient's dysphagia, weight loss, and abnormal CT imaging findings.

A repeat CT of the abdomen and pelvis with contrast was obtained. Findings redemonstrated a large loculated right lower lobe abscess with multiple air-fluid levels. A large $9.0 \times$ $8.7 \times 10.0 \mathrm{~cm}$ cystic mass in the head of the pancreas was seen along with focal distal esophageal thickening and destructive soft tissue lesions in the L3 vertebral body and left lateral 6th rib. Given his alcoholism and cavitary lung lesion, the patient was placed on negative pressure isolation and was ruled out for active pulmonary tuberculosis. Further laboratory studies including tumor markers included a CA 19-9 of $9 \mathrm{U} / \mathrm{mL}$ (reference range 0-35 U/mL), CA 125 of $68.0 \mathrm{U} / \mathrm{mL}$, and AFP of $1.4 \mathrm{ng} / \mathrm{mL}$ (reference range $0-9 \mathrm{ng} / \mathrm{mL}$ ).

Endoscopic workup revealed a fungating mass in the distal esophagus with suspicion of fistulizing disease to the lung (Fig. 1). The lesion was biopsied extensively as it was suspicious for malignancy. The stomach appeared unremarkable while the duodenum showed significant inflammation with nonbleeding clean-based ulcers. EUS revealed a hypoechoic lesion suggestive of a cyst in the head of the pancreas measuring $8.5 \times 12.1 \mathrm{~cm}$ in maximal cross-sectional diameter (Fig. 2). There were a few compartments without septa with the outer wall appearing thin. There was no associated mass. There was internal debris in the fluid-filled cavity. A diagnostic fine needle aspiration was performed using a Boston Scientific 19-G needle using a transgastric approach and sent for cytology, amylase, CEA, microbiology, anaerobic culture, 
and gram stain (Fig. 3). CEA of the cyst was $32 \mathrm{ng} / \mathrm{dL}$ (reference range $<192 \mathrm{ng} / \mathrm{dL}$ ) and amylase of the cyst was $6.9 \mathrm{U} / \mathrm{L}$ (reference range $<250 \mathrm{U} / \mathrm{L}$ ). No microbial growth was reported from the cystic lesion. An interventional radiology consult was obtained to sample the vertebral lesion.

Pathology results showed the distal esophageal mass to be squamous cell carcinoma. Cytology examination of the pancreatic cyst contained squamous cell carcinoma presumed to be from primary esophageal squamous cell cancer. Biopsy of the vertebral lytic lesion resulted to be squamous cell carcinoma.

\section{Discussion}

Pancreatic lesions are commonly encountered in the practice of the therapeutic endoscopist. Squamous cells detected upon sampling a pancreatic lesion represent a very unusual and unanticipated discovery. When identified, the astute clinician should focus his or her attention on uncovering a primary malignancy of squamous cell origin [5]. This may involve further history taking, gastrointestinal endoscopy, thorough otolaryngologic examination, pelvic examination, dermatologic examination, and potentially even PET-CT imaging to search for abnormal metabolic enhancement. Primary squamous cell carcinoma of the pancreas can only be confirmed after the metastatic workup is complete as the rate of primary squamous cell cancer of the pancreas occurs at a rate of $0.7 \%$ [5]. Even so, the diagnosis of a pure squamous cell cancer of the pancreas is debated and not specified as a distinct entity by the World Health Organization [6].

Malignancies that have been reported to metastasize to the pancreas include renal cell carcinoma, melanoma, breast, lung, liver, and colorectal cancers. $2 \%$ of all pancreatic tumors are due to these metastases. When metastases do occur, there is no specific predilection for any region of the pancreas [6]. The behavior of pancreatic malignancies, whether metastatic or primary adenocarcinoma, may present similarly in clinical history and biochemical studies with elevated bilirubin and alkaline phosphatase levels if there is biliary obstruction. There may be slight differences in the appearance of imaging studies as CT and MRI in metastatic disease may show peripheral or homogeneous contrast enhancement as opposed to hypoenhancement seen in primary adenocarcinoma [6]. In addition, on detection with EUS, metastases to the pancreas were more likely to have well-defined margins compared to primary adenocarcinoma [6].

There have been some attempts to explain possible mechanisms for esophageal cancer metastasizing to the pancreas. Notably, there is a complex anatomical pathway of the esophageal lymphatic network [7]. Intertwined arteriovenous vasculature has also been hypothesized as a viable mechanism of metastatic spread of esophageal cancer to end-organs [7].

In conclusion, pancreatic metastasis is quite a rare occurrence, and only a handful of cases in the literature have described esophageal squamous cell cancer with metastatic disease to the pancreas. It does not appear that a cystic lesion of the pancreas with metastatic squamous cell carcinoma has previously been reported since the few case reports have described solid pancreatic lesions. In clinical scenarios when the first lesion was sampled and resulted to be squamous cells of the pancreas, a thorough search for a primary culprit lesion should be undertaken utilizing a multidisciplinary approach. 
Yoon et al.: Esophageal Squamous Cell Cancer with Pancreatic and Bone Metastases

\section{Statement of Ethics}

There are no ethical disclosures for any of the authors involved in this article.

\section{Disclosure Statement}

No source of funding was provided for this study. There were no potential competing interests.

\section{References}

1 Hariharan D, Saied A, Kocher HM. Analysis of mortality rates for pancreatic cancer across the world. HPB (Oxford). 2008;10(1):58-62.

2 Brijbassie A, Stelow E, Shami VM. Squamous Cell Carcinoma of the Pancreas: A Case Report and Review of Literature. Gastroenterol Res. 2014 Aug;7(3-4):102-4.

3 Quint LE, Hepburn LM, Francis IR, Whyte RI, Orringer MB. Incidence and distribution of distant metastases from newly diagnosed esophageal carcinoma. Cancer. 1995 Oct;76(7):1120-5.

4 Chan KW, Chan EY, Chan CW. Carcinoma of the esophagus. An autopsy study of 231 cases. Pathology. 1986 Oct;18(4):400-5.

5 Park C, Jang JY, Kim YH, Hwang EJ, Na KY, Kim KY, et al. A case of esophageal squamous cell carcinoma with pancreatic metastasis. Clin Endosc. 2013 Mar;46(2):197-200.

6 Eloubeidi MA, et al. The role of endoscopy in the evaluation and management of patients with solid pancreatic neoplasia. Gastrointest Endosc. 2016 Jan;83(1):17-28.

7 Shaheen 0, Ghibour A, Alsaid B. Esophageal Cancer Metastases to Unexpected Sites: A Systematic Review. Gastroenterol Res Pract. 2017;2017:1657310. 

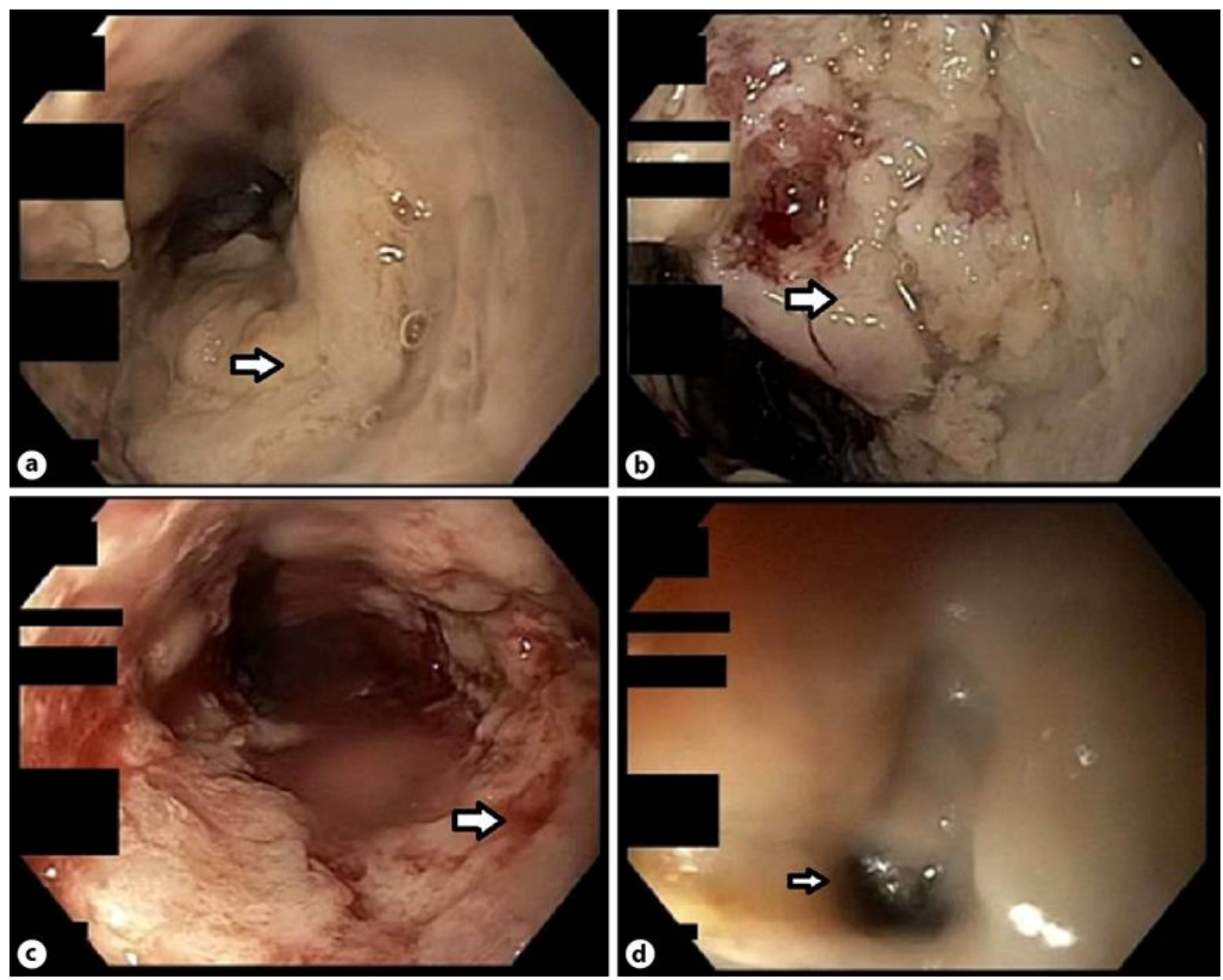

Fig. 1. Fungating mass in esophagus seen on endoscopy with suspected fistula (arrow). a Initial endoscopic visualization of the distal esophageal fungating mass lesion, which was biopsied extensively. b Ulcerated, fungating mass lesion in the distal esophagus. c Contact bleeding of the distal esophageal fungating mass lesion. $\mathbf{d}$ Appearance of fistulization of the distal esophageal mass. 


\section{Case Reports in Gastroenterology}
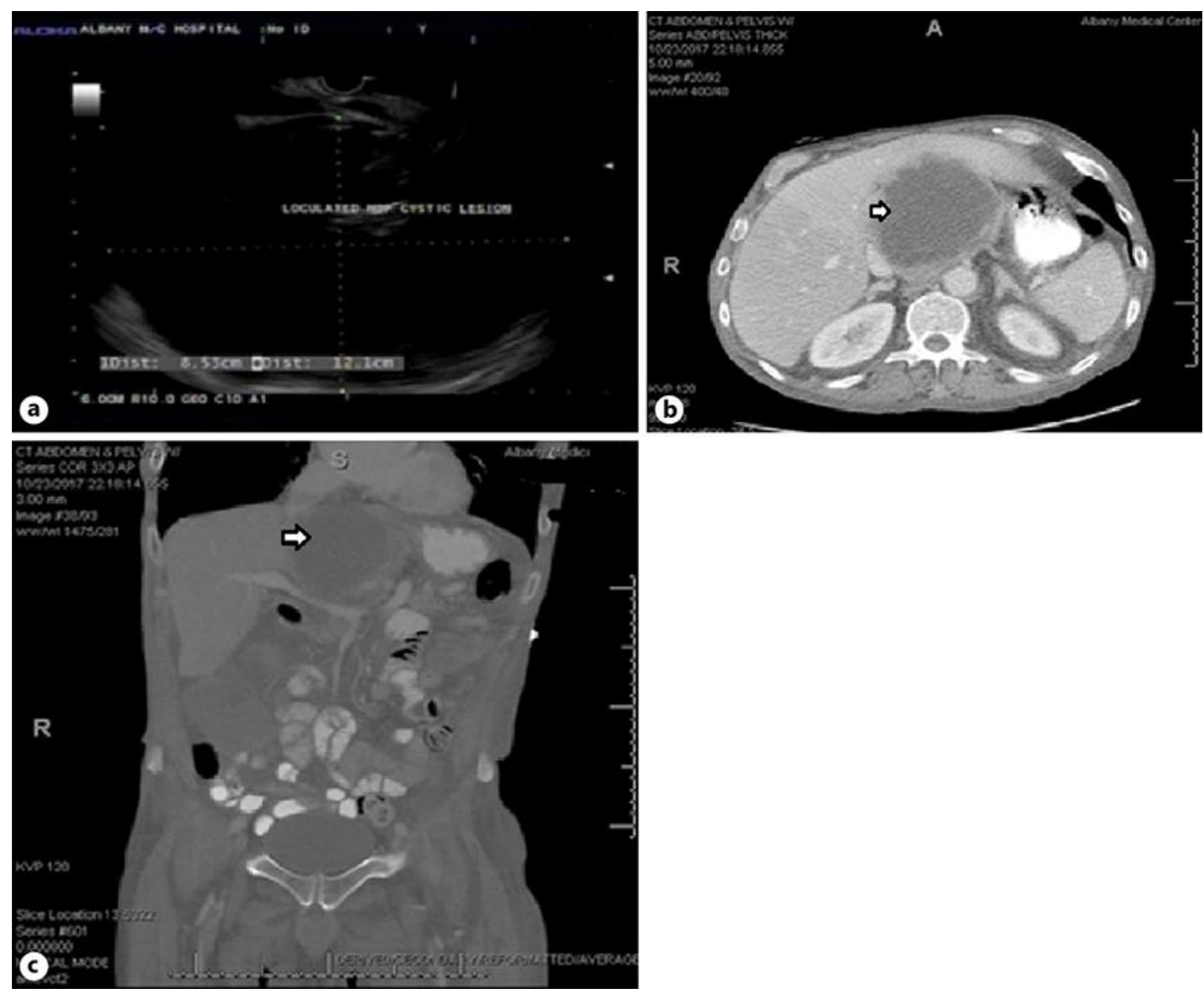

Fig. 2. Endoscopic ultrasound and CT scan showing pancreatic head cyst. a Endoscopic ultrasound image of the head of the pancreas cyst measuring $8.5 \times 12.1 \mathrm{~cm}$. This was trained with a 19-G Boston Scientific needle. $\mathbf{b}$ CT of the abdomen (axial view) showing hypoenhancement of the cyst in the head of the pancreas. c CT of the abdomen (coronal view) again demonstrating the large hypoenhancing cyst in the head of the pancreas. 


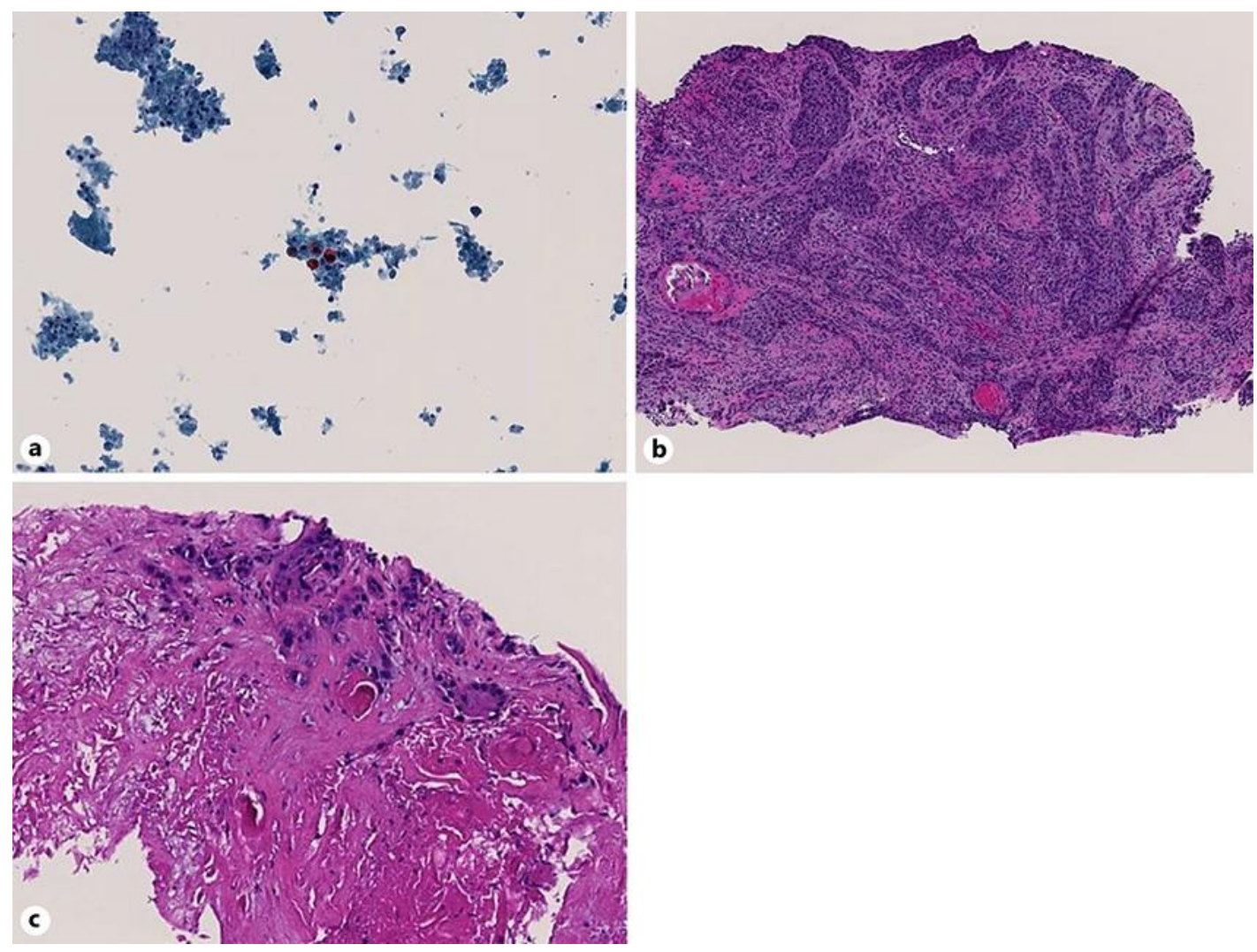

Fig. 3. a Fine needle aspirate of the pancreatic head showing a group of markedly atypical epithelial cells in the background of extensive necrosis, consistent with carcinoma. $\mathbf{b}$ Biopsy of distal esophagus showing infiltrating cords of malignant squamous cells with associated desmoplastic reaction, consistent with moderately differentiated invasive squamous cell carcinoma $(\times 10)$. c Biopsy of L3 vertebral body showing metastatic carcinoma, positive for p40 and p63, which is morphologically and phenotypically consistent with squamous cell carcinoma $(\times 20)$. 